\title{
Fly Facility Shared Resource
}

National Cancer Institute

\section{Source}

National Cancer Institute. Fly Facility Shared Resource. NCI Thesaurus. Code C39406.

The Fly Facility Shared Resource provides housing for collection of the standard wild type and mutant strains of Drosophila melanogaster and all services related to maintenance of fly stocks. 